\title{
Traditional microclimate management and manipulation in Tanzanian agriculture
}

\author{
C. J. Stigter (Section Agricultural Physics, Physics Department, \\ University of Dar es Salaam, Tanzania)*
}

Received 28 February 1985; accepted 1 April 1985

\begin{abstract}
Based on a newspaper contest and related literature research a review is given of practices by which traditional Tanzanian farmers manage and modify the microclimate of their crops and agricultural products.

Key-words: microclimate modification, traditional farming, Tanzania, shading, mulching, wind protection, surface properties, drying, storage, mechanical impact of rain and hail, ethnoscientific approach.
\end{abstract}

Introduction. In an ethnoscientific approach of research to increase low-input agricultural production, an important participatory component is advocated in farming systems research (Brokensha et al., 1980). This should start with consultations of the local communities on indigenous knowledge. An interpretation of the response should be tried in confrontation with existing scientific knowledge.

In a local newspaper contest in Tanzania, in 1980, information was collected on methods by which traditional farmers manage and manipulate, deliberately or inadvertently, the microclimate of their crops in the field and their agricultural products in drying and storage practices.

Classification problems. Detailed classification of environmental factors is one of the critical elements in small farm development that are largely or entirely omitted in most current systems of agricultural research and development (Harwood, 1979). This is not only true for a quantitative classification in forecasting of weather events and elements but even in a descriptive sense. Tropical micrometeorology/climatology must be considered a neglected research field (Stigter, 1984). Only two older descriptive sources of information existed (Acland, 1971; Wilken, 1972) with which our collected examples in least studied areas of traditional knowledge could be compared. Therefore a classification had to be developed for the purpose of systematizing such examples. This was not without difficulties which were partly due to the multi-purpose use and multi-effect functioning of many traditional modifications and partly due to differences in approach of the agronomic and meteorological disciplines concerned.

* Present address: c/o Agricultural University, Department of Physics and Meteorology, Duivendaal 1, 6701 AP, Wageningen, Netherlands. 


\section{J. STIGTER}

Least known. Indigenous techniques of shading, mulching, wind protection and modification at/of the surface are most important and least studied. For example, in shade management the literature is almost completely agronomic and a micrometeorological quantification is only available for extremely simple crop geometry. More is known and less is controversial on micrometeorological effects of mulching other than shade effects but our specific examples collected confirm the necessity for the tropics of a more comprehensive definition of the concept 'mulch', more in line with traditional thinking. On windbreak and wind reduction research pertinent to tropical low-input agriculture one has to state that it is non-existent, but we collected many examples of such traditional techniques which need to be studied quantitatively and from the point of view of the cause-and-effect relationships implied. Finally, a large variety of equally ill-studied examples could be classified, as traditionally understood, under the one heading of modification of surface properties with the purpose to modify the environmental impact on such surfaces. The drying and wetting examples suggest an indigenous empirical knowledge on surface energy balances.

Better known. Examples of traditional drying and storage practices and protection from mechanical impact of rain and hail are much better documented. But many intriguing methods are again only empirical and have never been studied as far as quantification of environmental factors in the tropics are concerned. It appears that underground storage is one of the few traditional manipulation methods that has recently attracted new attention for scientific research.

Conclusion. Tropical micrometeorology and microclimatology focussing on quantification of environmental factors in traditional farming systems and on operational classification of environmental information for weather advisories for such low-input agriculture (Stigter, 1984) can play a much more important role in development of tropical subsistence and small cash-crop agriculture.

Acknowledgements. Efforts of contest participants are gratefully acknowledged. Contest and related research were funded by the Directorate General of International Cooperation (DGIS), Ministry of Foreign Affairs, The Hague, Netherlands.

\section{References}

Acland, J. D., 1971. East African crops, FAO/Longman, London, $252 \mathrm{pp}$.

Brokensha, D., D. M. Warren \& O. Werner, 1980. Indigenous knowledge systems and development. University Press of America, Lanham, $460 \mathrm{pp}$.

Harwood, R. R., 1979. Small farm development. Westview Press, Boulder (CO), 160 pp.

Stigter, C. J., 1984. Forecasting and weather services for agriculture in Africa. Ch. 62 in: D. L. Hawskworth (Ed.), Advancing agricultural production in Africa. Proceedings CAB 1st Scientific Conference. CAB, Farnham Royal (Slough), 454 pp.

Wilken, G. C., 1972. Microclimate management by traditional farmers. Geographical Review 62: 544566 . 
This synopsis is based on a report entitled 'Microclimate management and manipulation by traditional farmers in Tanzania. Final contest report'. Section Agricultura' Physics, Physics Department, University of Dar es Salaam (Tanzania), 1985. 23 pp., 42 refs. English.

Available as paper copy (order R036P, free of charge for those working in a developing country, $f 20$ including postage for others) or microfiche (order R036M, f 12.50 including postage) at: NARD, clo Pudoc, P.O. Box 4, 6700 AA Wageningen, Netherlands (telex 45015 blhwg nl).

\section{Effect of pen size on the development of agonistic behaviour ${ }^{1}$ in piglets}

G. J. Lammers and W. G. P. Schouten (Department of Animal Husbandry, Agricultural University, Marijkeweg 40, 6709 PG Wageningen, Netherlands)

Received 29 January 1985; accepted 4 April 1985

Abstract. The development of agonistic behaviour was studied during the first 8 weeks of life of piglets housed in pens of $28 \mathrm{~m}^{2}, 6.7 \mathrm{~m}^{2}$ and $3.5 \mathrm{~m}^{2}$. Litter size was $7-9$ piglets. The research was done by frequential and sequential analysis of behavioural interactions between piglets.

Key-words: agonistic behaviour, development, pig, piglet, pen size, sequential analysis.

Introduction. The development of intensive pig husbandry during the past 10-20 years has greatly altered the circumstances under which piglets are reared. While it is evident that floor area per piglet has been much reduced, there is reason to assume that the size of these modern pens has become too small for the development of normal agonistic behaviour. A preliminary study showed that the development of agonistic behaviour of piglets reared in a small pen was quite different from piglets grown up in a large pen (D. J. Dijk, personal communication). In the present study we compared the development of agonistic behaviour of piglets housed in 3 different pen sizes.

Material and methods. Videorecordings were made of behavioural interactions between piglets within 4 litters during the first 8 weeks of life. Two litters were housed

${ }^{1}$ Agonistic behaviour is all the behaviour between aggression and flight. 